were consistent with UST safety profile in other studied indications.

Conclusion UST showed efficacy in treatment of active SLE vs PBO and comparable safety warranting further investigation. UST may work via a novel mechanism of action in SLE.

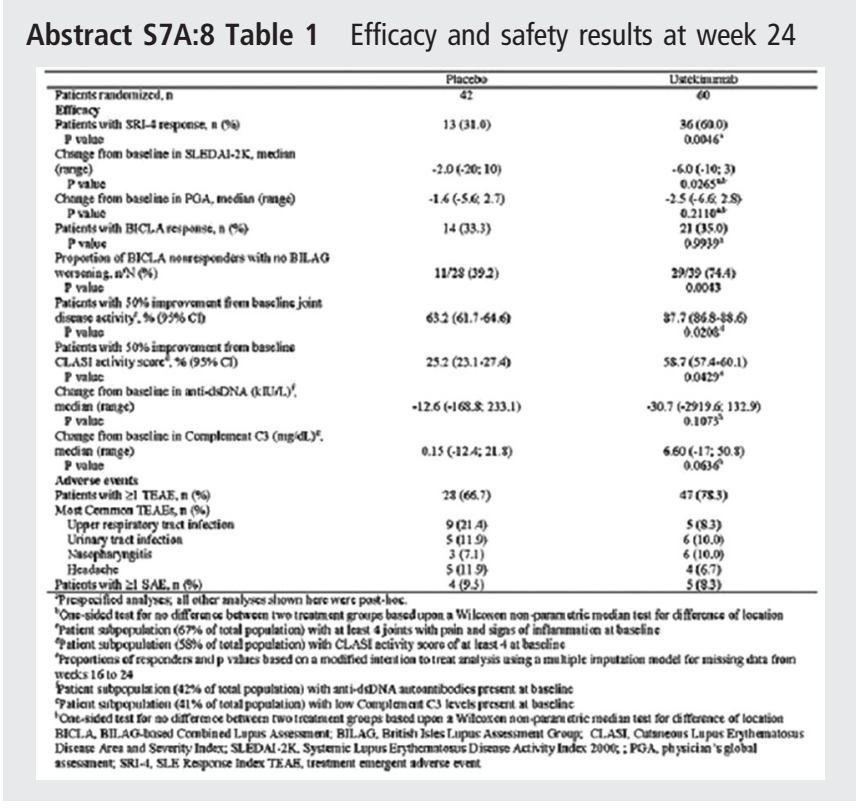

S7d - PRO

\section{S7D:4 THE RELATIONSHIP BETWEEN HEALTH-RELATED QUALITY OF LIFE AND REMISSION IN PATIENTS WITH SYSTEMIC LUPUS ERYTHEMATOSUS: A LONGITUDINAL COHORT STUDY}

MW Tsang-a Sjoe, IE Bultink, M Heslinga, AE Voskuyl. Amsterdam Rheumatology and immunology Centre at VU University Medical Centre, Amsterdam, The Netherlands

\subsection{6/lupus-2018-abstract.46}

Aim To investigate the relationship between health-related quality of life (HRQoL) and remission as a target in a treatto-target approach of systemic lupus erythematosus (SLE) in a longitudinal observational cohort study.

Methods HRQoL was assessed with the physical and mental component score (PCS and MCS, respectively) of the SF-36 questionnaire and adjusted for the Dutch general population

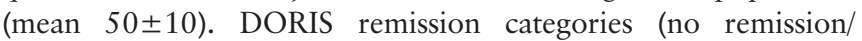
remission on therapy/remission off therapy) were applied 1. Determinants of PCS and MCS were identified with simple linear regression analyses. Association between remission and HRQoL was assessed with General Equation Estimation (GEE) models.

Results Data from 154 patients with 2 years of follow-up were analysed. Patients were mostly female (89\%) and Caucasian $(69.5 \%)$. Remission off therapy was present in $27.3 \%$ of patients, $18.1 \%$ were in remission on therapy, and $54.5 \%$ were not in remission. Mean PCS at baseline was 38.1 $( \pm 11.1)$ and mean MCS was $46.3( \pm 10.6)$. Patients in remission (as defined by remission on or off therapy) had higher SF-36 scores in all subdomains compared to patients not in remission. PCS was positively associated with employment and remission, while negatively associated with ESR, patient global assessment, SLE-damage- index, prednisone use, immunosuppressant use, and body mass index. MCS was positively associated with Caucasian ethnicity and negatively associated with patient global assessment.

PCS at the last visit was higher in patients in remission during 2 years $(n=44)$ compared to patients $(n=44)$ who were never in remission during 2 years of observation (mean 45.9 vs mean $36.8, \mathrm{p}<0.001$, respectively).

In GEE analysis, a gradual and statistically significant increase of PCS was observed from patients not in remission (mean PCS 36.0) to remission on therapy (41.8) to remission off therapy (44.8). No significant difference in MCS was found between remission states.

Conclusion We show a longitudinal relationship between PCS - but not MCS - and remission, which supports the validity of DORIS remission criteria as a treatment goal in SLE. A lack of association between MCS and remission might be explained by near-normal MCS scores in our cohort. Secondly, non-disease related factors might more importantly influence MCS.

\section{S7D:5 THE DIAGNOSTIC PHASE OF LUPUS - BEING IN A STANDSTILL-OF-LIFE}

${ }^{1} \mathrm{~J}$ Lisander Larsen, ${ }^{2} \mathrm{EOC}$ Hall, ${ }^{1} \mathrm{~S}$ Jacobsen, ${ }^{3} \mathrm{R}$ Birkelund. ${ }^{1}$ Copenhagen Lupus and Vasculitis Clinic, Copenhagen, Denmark; ${ }^{2}$ Section of Nursing, Department of Public Health, Aarhus University, Aarhus, Denmark; ${ }^{3}$ Institute of Regional Health Research, University of Southern Denmark and Lillebaelt Hospital, Vejle, Denmark

\subsection{6/lupus-2018-abstract.47}

Purpose To investigate the changes in basic life conditions over time from the perspective of female patients with systemic lupus erythematosus (Lupus). This presentation concerns experiences around the diagnostic phase of Lupus.

Method From 2013 to 2015, 43 individual interviews were performed with 15 female patients. Data were analysed according to the methodology of Human Science Phenomenology, which aims at collecting a common meaning-structure of human experiences. By considering basic condition of time, space, body and relationships, deeper knowledge of patient experiences can be reached.

Results Mean age was 45.6 years and mean disease duration 14.8 years. The time to diagnosis after the first symptoms varied from 2-54 months (mean: 21 months, SD: 16 months). The essential experience of going through the diagnostic phase was found to be in a Standstill-in-life constituted by three existential themes:

1. The experience of an altered perception of time and space while being exposed to the many medical examinations and tentative diagnosis situated the patient in a passive stance while waiting for clarification.

2. The acute or changing symptoms made daily life uncertain as the normal bodily reliance changed and interpreted as standing on an uneven ground.

3. Having the final Lupus diagnosis represented a deep existential change in personal relationships with self and others, and marked a substantial turning point in life.

Conclusion The diagnostic phase of Lupus is often protracted over several years. This study shows how going through the diagnostic phase initiates a significant change in the basic life 
Abstract S7D:4 Table 1

-Association between PCS and remission, adjusted for age and SDI

\begin{tabular}{|c|c|c|c|c|c|c|c|}
\hline & & & Crude & & & Adjusted & \\
\hline & $\begin{array}{l}\text { Mean PCS } \\
( \pm S D)\end{array}$ & B & $95 \% \mathrm{Cl}$ & $p$-value & B & $95 \% \mathrm{Cl}$ & $p$-value \\
\hline $\begin{array}{l}\text { No } \\
\text { remission }\end{array}$ & $36.0(10.9)$ & ref & & & ref & & \\
\hline $\begin{array}{l}\text { Remission } \\
\text { on therapy }\end{array}$ & $41.8(10.0)$ & 6.3 & $3.2-9.3$ & $<0.001$ & 6.2 & $3.3-9.0$ & $<0.001$ \\
\hline $\begin{array}{l}\text { Remission } \\
\text { off therapy }\end{array}$ & $44.8(10.4)$ & 8.2 & $5.3-11.2$ & $<0.001$ & 8.3 & $5.4-11.1$ & $<0.001$ \\
\hline
\end{tabular}

-Association between MCS and remission, adjusted for ethnicity

\begin{tabular}{|c|c|c|c|c|c|c|c|}
\hline & & & Crude & & & Adjusted & \\
\hline & $\begin{array}{l}\text { Mean MCS } \\
( \pm S D)\end{array}$ & B & $95 \% \mathrm{Cl}$ & p-value & B & $95 \% \mathrm{Cl}$ & $\begin{array}{l}\text { p- } \\
\text { value }\end{array}$ \\
\hline No remission & $46.1(10.6)$ & Ref. & & & Ref. & & \\
\hline $\begin{array}{l}\text { Remission on } \\
\text { therapy }\end{array}$ & $49.3(10.5)$ & 2.9 & $0.1-5.7$ & 0.041 & 2.3 & $-0.5-5.1$ & 0.112 \\
\hline $\begin{array}{l}\text { Remission off } \\
\text { therapy }\end{array}$ & $46.8(10.1)$ & 0.8 & $-1.7-3.4$ & 0.52 & 0.4 & $-2.1-3.03$ & 0.739 \\
\hline
\end{tabular}

conditions. The phase represents a demanding existential situation. Support through the diagnostic phase, by considering the patient's existential challenge and incorporate this in rehabilitation programmes would emancipate patients through a demanding time and be a novel contribution to patient support.

\section{S7D:6 GOING VIRAL IN RHEUMATOLOGY: A RAPID, COST- EFFECTIVE METHOD OF OBTAINING PATIENT OPINION ABOUT RESEARCH IN SLE AND APS}

T McDonnell, C Wincup, A Rahman, I Giles. University College London, UK

\subsection{6/lupus-2018-abstract.48}

Purpose It is important to access opinions from patients in designing research into systemic lupus erythematous (SLE) and/or antiphospholipid syndrome (APS). It is difficult to obtain useful information from large numbers of unselected patients in a short period of time. There is a lack of published research about how to achieve this objective. On-line surveys and use of social media offer a potential method to address this challenge. We developed a novel approach to access patient opinion regarding key objectives for mechanistic research in SLE and APS.

Methods We developed a one-page lay summary of a research project concerning investigation of serine proteases in patients with APS and SLE. This is a mechanistic laboratory project with potential future relevance to management of these diseases. Both the lay summary and an accompanying 9-question survey were refined with the help of an expert patient and patients' charities, then disseminated as an online survey. The survey was open for four weeks, and was publicised via social media (Twitter, Facebook) and through the websites of LUPUS UK and APS Support UK. The survey data were then analysed and total project cost was $£ 26$.

Results Of 527 respondents, 520 confirmed having been diagnosed with SLE and/or APS. The majority of respondents were very positive about the research, expressing strong interest in its mechanistic basis. We provided a free text box for respondents to express their opinions about the most important research topics in SLE and APS. 277 respondents 